\title{
Assessing Suicide Reporting in Top Newspaper Social Media Accounts in China: Content Analysis Study
}

Kaisheng Lai ${ }^{1}$, PhD; Dan $\mathrm{Li}^{1}$, BA; Huijuan Peng ${ }^{1}$, BA; Jingyuan Zhao ${ }^{1}$, BA; Lingnan $\mathrm{He}^{2,3,4}, \mathrm{PhD}$

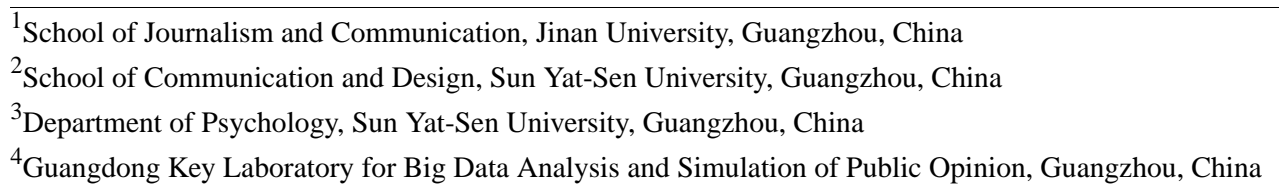

Corresponding Author:

Lingnan $\mathrm{He}, \mathrm{PhD}$

School of Communication and Design

Sun Yat-Sen University

No. 132 Waihuan East Road

Higher Education Mega Center

Guangzhou,

China

Phone: 8602039331935

Email: heln3@mail.sysu.edu.cn

\begin{abstract}
Background: Previous studies have shown that suicide reporting in mainstream media has a significant impact on suicidal behaviors (eg, irresponsible suicide reporting can trigger imitative suicide). Traditional mainstream media are increasingly using social media platforms to disseminate information on public-related topics, including health. However, there is little empirical research on how mainstream media portrays suicide on social media platforms and the quality of their coverage.

Objective: This study aims to explore the characteristics and quality of suicide reporting by mainstream publishers via social media in China.

Methods: Via the application programming interface of the social media accounts of the top 10 Chinese mainstream publishers (eg, People's Daily and Beijing News), we obtained 2366 social media posts reporting suicide. This study conducted content analysis to demonstrate the characteristics and quality of the suicide reporting. According to the World Health Organization (WHO) guidelines, we assessed the quality of suicide reporting by indicators of harmful information and helpful information.

Results: Chinese mainstream publishers most frequently reported on suicides stated to be associated with conflict on their social media (eg, 24.47\% [446/1823] of family conflicts and 16.18\% [295/1823] of emotional frustration). Compared with the suicides of youth $(730 / 1446,50.48 \%)$ and urban populations $(1454 / 1588,91.56 \%)$, social media underreported suicides in older adults $(118 / 1446,8.16 \%)$ and rural residents $(134 / 1588,8.44 \%)$. Harmful reporting practices were common (eg, 54.61\% [1292/2366] of the reports contained suicide-related words in the headline and 49.54\% [1172/2366] disclosed images of people who died by suicide). Helpful reporting practices were very limited (eg, 0.08\% [2/2366] of reports provided direct information about support programs).

Conclusions: The suicide reporting of mainstream publishers on social media in China broadly had low adherence to the WHO guidelines. Considering the tremendous information dissemination power of social media platforms, we suggest developing national suicide reporting guidelines that apply to social media. By effectively playing their separate roles, we believe that social media practitioners, health institutions, social organizations, and the general public can endeavor to promote responsible suicide reporting in the Chinese social media environment.
\end{abstract}

(JMIR Ment Health 2021;8(5):e26654) doi: 10.2196/26654

\section{KEYWORDS}

suicide; suicide reporting; mainstream publishers; social media; WHO guidelines 


\section{Introduction}

Suicide is a public health problem of global concern. More than 800,000 suicide deaths occur every year, meaning that more than 2000 people die by suicide every day [1]. To deal with this problem, the World Health Organization (WHO) has proposed the need to highly prioritize suicide prevention on global public health and public policy issues [2]. Suicide is a multidimensional issue related to various factors that can be facilitated by psychological, biological, social, and environmental factors $[3,4]$. Mass media coverage is a significant agent in the social construction of reality in today's world, which may affect people's exposure to suicide behaviors, especially for vulnerable groups [5]. Accordingly, researchers have determined that the role of mass media in suicidal behavior warrants serious and focused attention [6].

Research on the negative effect of suicide reporting (commonly known as the Werther effect) in the academic field can be traced back to 1974. Philips [7] found that publishing suicide stories in British and American newspapers led to an immediate increase in the number of suicides in the region. Since then, studies have confirmed the imitation effect caused by media reporting [8,9] and further illustrated that this imitation effect can be aggravated when suicide is repeatedly reported [10] or depicted sensationally and graphically [11] or when the subject is a celebrity $[12,13]$. Subsequently, scholars have noted the potential effect of the media on suicide prevention. Empirical research conducted in Switzerland [14], Australia [15], and Hong Kong [16] has indicated that promoting education by introducing reporting guidelines to media practitioners could effectively improve the quality of suicide reporting. By conducting long-term experiments in Austria, researchers found that the application of media guidelines and media campaigns in the city of Vienna led to a reduction of more than $80 \%$ in the subway suicide rate in 6 months [17-19].

Given the effectiveness of media guidelines in suicide prevention, in 2008, WHO and the International Association for Suicide Prevention released professional criteria for suicide reporting for media practitioners [20]. Consequently, some scholars have begun to evaluate the extent to which suicide reporting followed these guidelines; these evaluation studies were concentrated in Western countries and showed that the implementation of the guidelines varied [21,22]. Recently, research and evaluation on suicide reporting in Asia has increased; generally, studies have found a low level of compliance with WHO guidelines [23-26]. When assessing the quality of suicide reporting in Indian newspapers, Armstrong et al [24] found a considerable amount of harmful information and minimal educational information. If we consider that Asia has the largest suicide numbers on the globe [27], however, we find that the amount of empirical evidence we have on the quality of suicide reporting in the continent is quite limited.

Overall, the literature on the evaluation of suicide reporting has focused on traditional media, especially newspapers; with the emergence of Web 2.0 technology, however, social media is becoming an indispensable part of public information dissemination [28]. In the health field, people increasingly rely on social media for health communication, and social media plays a crucial role in the construction of general cognition, attitude, and behavior in the field $[29,30]$. Thus, many media outlets have allocated their resources toward social media platforms [31], and these accounts have shown tremendous influence. The Twitter account of the New York Times has nearly 500 million followers; similarly, People's Daily has more than 100 million followers on Sina Weibo. Language style, staff structure, and frequency of posting of mainstream media on social media platforms differs from traditional media platforms [32-34], and research has shown that mainstream media's language style on social media is more vivid, concise, and easy to understand [34]. Do the differences between traditional and social media platforms affect mainstream media's reporting preferences or content quality? Based on this question, investigating how the mainstream media reports on public issues via social media has recently become a challenging research topic.

An empirical study found that American mainstream outlets showed preferential interest in disseminating information related to psychiatric disorders on Twitter, and media attention to different mental health disorders determines followers' retweet responses [35]. Regarding suicide, a recent study evaluated news publishers' reporting of suicide on Facebook and found that news articles often provided harmful elements to readers, whereas positive elements were relatively rare [36]. To the best of our knowledge, the study has been the only one to investigate news publishers' suicide reporting on a social media platform, and it focused primarily on English-speaking countries. It remains unknown how mainstream media reports suicide via social media in different cultural contexts, especially in China.

Suicide remains a significant public health issue in China today. In 2019, nearly 140,000 people died by suicide in China, second only to India in the world [37]. Although a few scholars have assessed suicide reporting in China, these studies were limited to specific regions or focused on traditional media $[23,25,38]$. Using WHO guidelines, Fu et al [23] compared suicide reporting of newspapers in Hong Kong, Taiwan, and Guangzhou; the findings indicated that reports in the three regions were mostly inconsistent with WHO recommendations. Chu et al [25] evaluated suicide reporting in China's most influential newspapers and internet-based media, and the results showed that compliance with the guidelines was very low for 4 of the 12 recommendations (eg, less than $5 \%$ of stories provided information on where a person could go for help). To the best of our knowledge, no nationwide research has investigated the compliance of suicide reporting published by Chinese mainstream publishers on social media platforms. Thus, the aim of this study is 2-fold and the research questions are as follows: What are the characteristics of suicide reporting of mainstream publishers via social media? What is the extent to which their suicide reporting follows WHO guidelines?

\section{Methods}

\section{Newspapers Selected}

We obtained the top 100 media list of comprehensive communication power from a 2018 national online survey [39]. 
Since the number of followers directly affects the visibility of reports, the number of followers on Weibo, one of the most popular platforms in China [40,41], can represent the publisher's influence. We ranked publisher Weibo accounts according to the number of followers on November 1, 2019, and categorized them as national or local. We then selected the top 5 national (People's Daily, China Daily, Global Times, Guangming Daily, and China Youth News) and local (Beijing News, Shanghai Morning Post, New Express, Yangtze Evening Post, and Southern Metropolis Daily) newspapers for further study. Due to access restrictions, we were not able to collect data from New Express and replaced it with Chutian Metropolis Daily, which ranked sixth in local newspapers. Each publisher had more than 10 million followers on their Weibo accounts.

\section{Data Extraction}

We used the open-source web data crawling tool Octopus to crawl the data by keyword search via the application programming interface of Weibo. Specifically, we designed a keyword search strategy that contained a core word (ie, "suicide"), a synonym (ie, "Zijin," which means suicide in Chinese), and 8 hyponyms of common suicide methods in China (ie, "jumping off a building," "jumping off a bridge," "jumping into a river," "drinking pesticides," "taking drugs," "wrist cutting," "hanging," and "charcoal burning") [42]. Initially, we obtained 5956 posts published between August 11, 2011, and November 16, 2019, with at least one of the above keywords. These posts were then filtered based on the following criteria taken from prior research: event depicted in the post must have been a completed suicide or suicide attempt [24,25]; event must have occurred in China and among the Chinese population (ie, posts on foreigners who died by suicide in China and on Chinese people who died by suicide overseas were omitted) [23]; suicide events associated with murder or violence were omitted [25]; post must have been a narrative (ie, fictional, editorials, and single-sentence posts, called flashes, were omitted) [23]; and posts irrelevant for our study were omitted (eg, a post that stated "Staying up late equals to chronic suicide"). In total, we obtained 2366 posts (2363 original posts and 3 reposts) about suicide reporting (Figure 1).

Figure 1. Flowchart of mainstream publishers selected and data extraction.

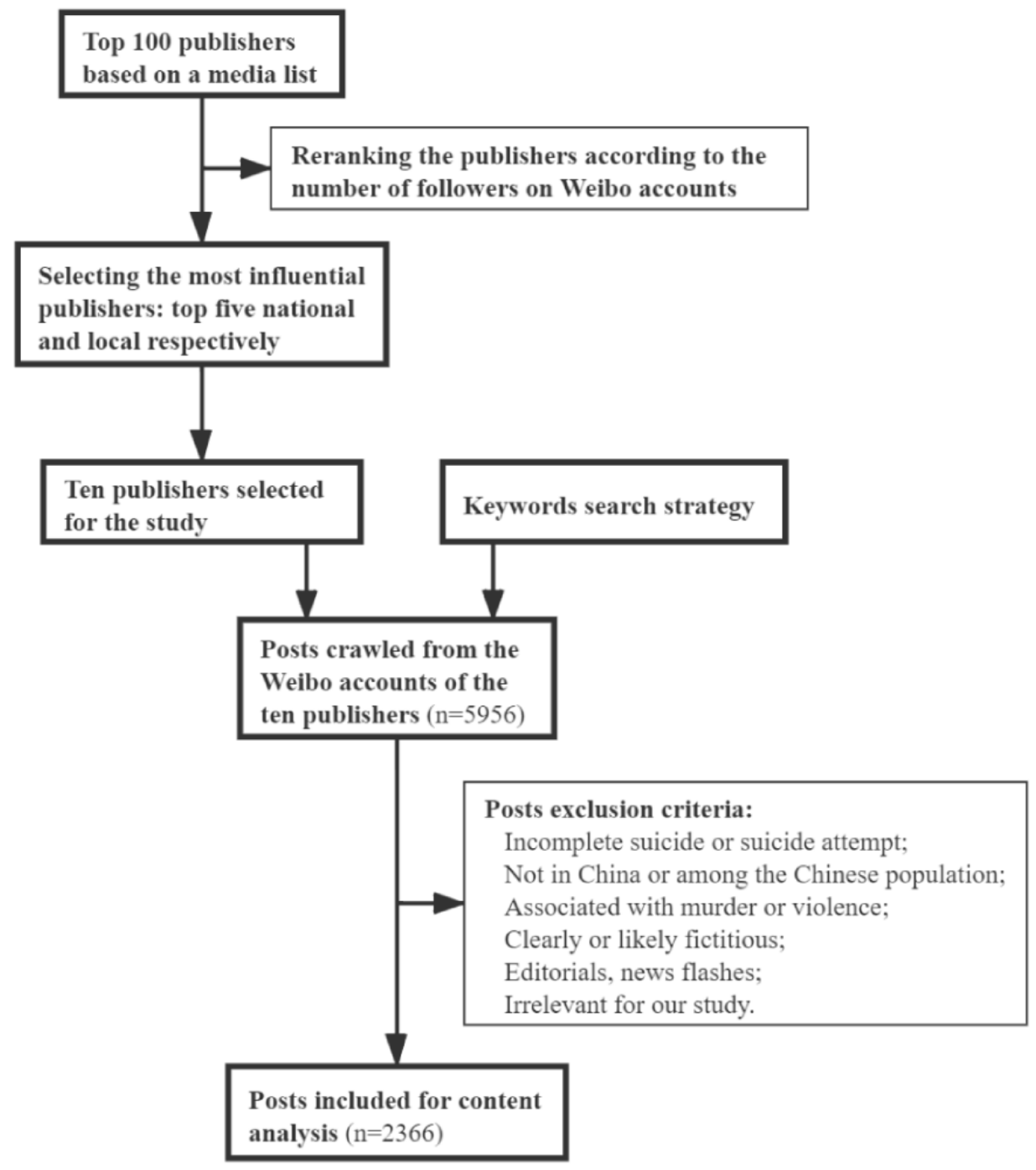




\section{Content Analysis}

We conducted content analysis based on prior evaluation research [21-26]. First, we extracted descriptive data to address the first research question that included the following 3 categories of suicide reporting characteristics: (1) text characteristics (ie, publisher name, publication time, and whether the post contained pictures or videos); (2) suicide event characteristics, including the type (ie, completed suicide or attempt), site (ie, urban or rural area), method (ie, jumping off a building, jumping off the bridge, jumping into the river, drinking pesticides, taking drugs, wrist cutting, hanging, charcoal burning, other ways, or multiple ways), and cause (ie, family conflict, emotional frustration, financial difficulty, interpersonal conflict, mental disorder, study or work pressure, to avoid responsibility, physical disease, loneliness or solitude, other causes, or multiple factors) [42]; and (3) demographic characteristics of people who die by suicide, including gender (ie, female, male, or group suicidal event), age (ie, juvenile, youth, middle-aged, or older adults group), marital status (ie, unmarried, married, divorced, or widowed), and economic activity status (ie, student, economically active-employed, economically active-unemployed, or economically inactive) [43].
Second, we designed a social media evaluation framework based on the WHO guidelines to assess the quality of suicide reporting by mainstream publishers. We divided the content of the suicide reports into the categories harmful and helpful information $[20,24,36]$. The harmful information category included level of detail of the suicide description, disclosure of private information, and vividness of the reporting.

Despite their usefulness, the WHO guidelines were derived from press practices of traditional media, and the recommendations were not aligned with the features of social media. Hence, we adjusted several of the original items to improve the flexibility and applicability of the evaluation framework; for example, because social media posts do not have a layout order, avoid the prominent placement of suicide reporting was modified to avoid the inclusion of suggestive signs or emojis in suicide reporting. To improve the evaluation framework's scientificity and operability, we removed the item about disclosure of private information about the person who died by suicide from harmful information after consulting with relevant experts because the meaning of information is too broad to operationalize. Finally, we achieved an evaluation framework containing 11 dichotomous items (ie, present $=1$, absent $=0$ ). The structure of the evaluation framework and item definitions and examples are shown in Table 1.

Table 1. Evaluation framework for the quality of social media suicide reporting.

Dimension, subdimension, and item Example

\section{Harmful information}

\section{Level of detail of the suicide description}

Describes in detail the tools used for suicide or specific suicide actions, such as drug dosage.

Provides specific information about the site of suicide event, such as the exact name of the bridge, street, community, and so on.

\section{Disclosure of private information}

Includes photographs or videos showing images of the person who died.

Describes the content of the suicide note in detail.

Includes interviews of immediate family members of the person who died by suicide.

\section{Vividness of the reporting}

Attaches hashtags at the beginning or end of the post.

Uses suggestive characters or emoji to highlight the content.

Includes the word suicide directly in the headline or discloses the cause of suicide.

\section{Helpful information}

Relates suicidal behaviors with mental disorders such as depression.

Provides information on where to seek help such as a psychological consultation hotline or other public health service.

Provides professional knowledge about suicide prevention from psychologist experts or scholars.
"She took nearly 500 tablets of chlorpheniramine in her car."

"Weikang Hotel, Nujiang Town, Tongjiang County, Sichuan Province." $-{ }^{\mathrm{a}}$

"He expressed his apology to parents and left his bank card password in the suicide note."

"His father said in the interview that his daughter was often depressed after the accident."

\#The 13-year-old boy left home after being blamed by his father\# “!!!," “ "

"Confession failed, a man climbed to a high building to suicide."

"This pregnant woman suffered from postpartum depression."

"Beijing Huilongguan Hospital psychological crisis intervention hotline: 800-810-1117."

"The psychiatrists said that [positive psychological intervention] can completely change the situation of mental illness."

\footnotetext{
${ }^{\mathrm{a}}$ Not applicable.
} 
We selected 3 well-trained graduate students who had majored in journalism and communication for coding; they used an explicit coding framework. We conducted a reliability test based on 100 sample data items, finding the following: the interrater reliability of suicide reporting characteristics ranged from 0.78 to 0.98 with an average of .91 and that of suicide reporting quality ranged from 0.73 to 1.0 , with an average of 0.88 . Based on prior research, both parts of the framework indicated strong interrater reliability [44]. To bridge understanding deviations regarding the coding and reach consensus throughout the research process, we held regular meetings with the coders.

\section{Results}

\section{Analysis of Suicide Reporting}

The number of suicide reports varied considerably among the analyzed media accounts (see Table 2). Overall, the Global Times showed the largest number of suicide reports $(21.26 \%$, 503/2366), whereas Guangming Daily showed the smallest number $(0.89 \%, 21 / 2366)$, both being national publishers. In local publishers, the Shanghai Morning Posts showed the largest number $(19.65 \%, 465 / 2366)$, second only to the national publisher Global Times. From the perspective of time, the number of suicide reports varied considerably between 2011 to 2019; the year 2018 showed the largest number of suicide reports $(19.57 \%, 463 / 2366)$ and 2011 , the lowest $(1.61 \%$. 38/2366).

Table 2. Suicide reporting by national and local Chinese publishers $(\mathrm{n}=2366)$.

\begin{tabular}{ll}
\hline Newspaper name & Suicide reports, $\mathrm{n}(\%)$ \\
\hline Global Times & $503(21.26)$ \\
Shanghai Morning Post & $465(19.65)$ \\
Chutian Metropolis Daily & $420(17.75)$ \\
Beijing News & $330(13.95)$ \\
Yangtze Evening Post & $246(10.40)$ \\
People's Daily & $121(5.11)$ \\
Southern Metropolis Daily & $92(3.89)$ \\
China Daily & $87(3.68)$ \\
China Youth News & $81(3.42)$ \\
Guangming Daily & $21(0.89)$ \\
\hline
\end{tabular}

\section{Characteristics of Suicide Reporting on Social Media}

Most reported suicide events occurred in urban areas (1454/1588, 91.56\%; excluding 778 posts lacking information on site; see Table 3). Almost all suicide reporting disclosed the suicide method (2195/2366, 92.77\%), with jumping off buildings $(884 / 2195,40.27 \%)$ and jumping into rivers $(391 / 2195,17.81 \%)$ being the most commonly reported. Despite being one of the most popular suicide methods in South and East Asia [45], reported events of drinking pesticide ranked fourth $(172 / 2195$, $7.84 \%)$.

Nearly $80 \%(1823 / 2366,77.05 \%)$ of the reporting described the suicide attribution as stated in media reports, among these family conflict $(446 / 1823,24.47 \%)$, followed by emotional frustration $(295 / 1823,16.18 \%)$, financial difficulty $(199 / 1823$, $10.92 \%)$, and interpersonal conflicts $(196 / 1823,10.75 \%)$.

Regarding the demographic characteristics of people who died by suicide (Table 3), the number of females (1096/2326, $47.12 \%)$ was very close to males $(1117 / 2326,48.02 \%)$, and $4.86 \%(113 / 2326)$ reports were group suicidal events. More than $60 \%(1446 / 2366,61.12 \%)$ of suicide reporting disclosed the person's age, of which the youth group accounted for more than half $(730 / 1446,50.48 \%)$, followed by the juvenile (424/1446, 29.32\%), middle-aged (174/1446, 12.03\%), and older adults groups $(118 / 1446,8.16 \%)$. In addition, suicide reports on social media more frequently reported on suicidal behaviors of unmarried groups and students. 
Table 3. Descriptive characteristics of suicide reporting on social media $(n=2366)$.

\begin{tabular}{|c|c|}
\hline Characteristics & Values, n (\%) \\
\hline \multicolumn{2}{|l|}{ Suicide event characteristics } \\
\hline \multicolumn{2}{|l|}{ Event $(n=2366)$} \\
\hline Suicide attempt & $1308(55.28)$ \\
\hline Suicide death & $1058(44.72)$ \\
\hline \multicolumn{2}{|l|}{ Site $(n=1588)$} \\
\hline Urban area & $1454(91.56)$ \\
\hline Rural area & $134(8.44)$ \\
\hline \multicolumn{2}{|l|}{ Method $(n=2195)$} \\
\hline Jumping off building & $884(40.27)$ \\
\hline Jumping into river & $391(17.81)$ \\
\hline Other way & $212(9.66)$ \\
\hline Drink pesticide & $172(7.84)$ \\
\hline Jumping off bridge & $165(7.52)$ \\
\hline Hanging & $119(5.42)$ \\
\hline Taking medicine & $94(4.28)$ \\
\hline Wrist cutting & $60(2.73)$ \\
\hline Charcoal burning & $58(2.64)$ \\
\hline Multiples ways & $40(1.82)$ \\
\hline \multicolumn{2}{|c|}{ Attribution (factor) as stated in media reports $(\mathbf{n}=1823)$} \\
\hline Family conflict & $446(24.47)$ \\
\hline Emotional frustration & $295(16.18)$ \\
\hline Financial difficulty & $199(10.92)$ \\
\hline Interpersonal conflict & $196(10.75)$ \\
\hline Mental disorder & $172(9.43)$ \\
\hline Study or work pressure & $168(9.22)$ \\
\hline Other cause & $157(8.61)$ \\
\hline Avoid responsibility & $60(3.29)$ \\
\hline Physical disease & $55(3.02)$ \\
\hline Loneliness or solitude & $42(2.30)$ \\
\hline Multiple factors & $33(1.81)$ \\
\hline \multicolumn{2}{|l|}{ Demographic characteristics } \\
\hline \multicolumn{2}{|l|}{ Gender $(\mathbf{n}=\mathbf{2 3 2 6})$} \\
\hline Male & $1117(48.02)$ \\
\hline Female & $1096(47.12)$ \\
\hline Group suicidal event & $113(4.86)$ \\
\hline \multicolumn{2}{|l|}{ Age group (years; $n=1446$ ) } \\
\hline Youth (19 to 35$)$ & $730(50.48)$ \\
\hline Juvenile (below 18) & $424(29.32)$ \\
\hline Middle-age (36 to 65 ) & $174(12.03)$ \\
\hline Older adults (over 65) & $118(8.16)$ \\
\hline \multicolumn{2}{|l|}{ Marital status $(n=1292)$} \\
\hline Unmarried & $927(71.75)$ \\
\hline
\end{tabular}




\begin{tabular}{cl}
\hline Characteristics & Values, $\mathrm{n}(\%)$ \\
\hline Married & $324(25.08)$ \\
Divorced & $31(2.40)$ \\
Widowed & $10(0.77)$ \\
Economic activity status (n=1062) & $593(55.84)$ \\
Student & $364(34.27)$ \\
Economically active-employed & $60(5.65)$ \\
Economically inactive & $45(4.24)$ \\
Economically active-unemployed & \\
\hline
\end{tabular}

\section{Assessing Suicide Reporting Quality on Social Media Against WHO Guidelines}

Our study demonstrated that harmful reporting practices were widespread on Chinese social media (Table 4); $41.50 \%$ (982/2366) of suicide reporting contained 3 or more harmful instances of information, while only $5.92 \%$ (140/2366) of the suicide reporting did not have any harmful information. Further, the vividness of the reporting subdimension had the highest mean (mean 0.35 ), followed by disclosure of private information (mean 0.27), and level of detail of the suicide description (mean $0.22)$.

Regarding vividness of the reporting, more than half of the suicide reporting either directly used the word "suicide" or disclosed the reasons for suicide in the headlines, practices that deviate considerably from the WHO guidelines to word headlines carefully. It is worth noting that the use of internet elements has become common on social media platforms; on the topic, this study showed that $37.19 \%(880 / 2366)$ of the suicide reporting used suggestive symbols (eg, multiple exclamation points or emojis). Furthermore, 13.99\% (331/2366) of the suicide reporting attached hashtags at the beginning of the articles. These hashtags were highly visible because they were discussed by the public to a certain extent (eg, the hashtag \#26-year-old female teacher fell off the building\#).

Regarding the disclosure of private information, half $(1172 / 2366,49.54 \%)$ of the suicide reporting exposed images of the people who died, and nearly $30 \%$ (313/1172, 26.71\%) were not pixelated. Additionally, $11.33 \%$ (268/2366) of suicide reporting disclosed the suicide note, with $41.8 \%$ (112/268) of the notes coming from the person's social media platform (eg, on Weibo or WeChat). According to the WHO guidelines, social media posts and email information of people who die by suicide should not be disclosed, as these suicide notes may contain sensitive private information (eg, their debts or information on their interpersonal relationships).

Regarding level of detail of the suicide description, almost $24 \%$ $(568 / 2366,24.01 \%)$ of the suicide reporting described the suicide methods in detail (eg, "She closed the window, locked the door, and lit the charcoal fire"). Moreover, 20.08\% $(475 / 2366)$ of the suicide reporting provided specific information on the suicide site (eg, the exact names of streets, communities, or bridges).

Our results also indicated that Chinese mainstream publishers' suicide reporting on social media has significant deficiencies regarding the provision of helpful information: only 1 of all 2366 suicide reports included all the helpful information outlined in evaluation framework for this study; in contrast, more than $85 \%(2017 / 2366,85.25 \%)$ of the reporting did not provide any helpful information. WHO considers it important to emphasize the causal relationship between suicidal behavior and mental illness for suicide prevention efforts [20]. However, only $10.86 \%$ (257/2366) of the analyzed suicide reporting highlighted this relationship. Moreover, less than 6\% (137/2366, 5.79\%) of the suicide reporting provided suicide prevention knowledge for the public (eg, psychology experts' advice on suicide prevention or official suicide statistics to highlight the importance of the suicide issue). Furthermore, only 2 reports provided direct information about support programs, which are essential for vulnerable groups seeking help; in contrast, the WHO guidelines suggest mass media publishers list available sources of support (eg, psychological intervention hotlines and community resources) for those in need [20]. 
Table 4. Assessing suicide reporting quality on social media against the WHO guidelines ( $\mathrm{n}=2366$ ).

\begin{tabular}{ll}
\hline Items & Value, $\mathrm{n}(\%)$ \\
\hline $\begin{array}{l}\text { Harmful information } \\
\text { Vividness of the reporting }\end{array}$ & $1292(54.61)$ \\
$\quad$ Headline contains suicide-related words & $880(37.91)$ \\
$\quad$ Suggestive symbols or emojis used & $331(13.99)$ \\
$\quad$ Hashtag used & $1172(49.54)$ \\
Disclosure of private information & $376(15.89)$ \\
$\quad$ Exposure of images of people who died by suicide & $268(11.33)$ \\
$\quad$ Interviews with relatives of people who died by suicide & \\
$\quad$ Disclosure of the suicide note & $568(24.01)$ \\
$\quad$ Level of detail of the suicide description & $475(20.08)$ \\
$\quad$ Detailed description of the suicide method & \\
$\quad$ Detailed description of the suicide site & $257(10.86)$ \\
Helpful information & $137(5.79)$ \\
Emphasize relationship between suicide and mental disorders & $2(0.08)$ \\
Provide suicide prevention knowledge &
\end{tabular}

\section{Discussion}

\section{Principal Findings}

This study analyzed the characteristics of suicide reporting of the top 10 publisher accounts (in terms of number of followers) on Sina Weibo and assessed their suicide reporting quality against the WHO guidelines. Our analyses yielded the following findings: (1) Chinese mainstream publishers on social media most frequently reported on suicides that were stated to be associated with conflict and underreported suicides in older adults and rural residents, (2) these suicide reports provided widespread harmful information, especially concerning vividness of the reporting and disclosure of private information, and (3) these reports provided limited helpful information such as direct information about suicide support programs.

Analysis of suicide reporting characteristics revealed two features. First, the reporting of suicide events was found to be clickbait oriented, in which publishers tried their best to attract readers with a sensational and dramatic reporting style. Suicide is a complex phenomenon with multiple contributing factors. However, in this study, almost all suicide reports interpreted suicide as an unexpected event caused by a single factor, with interpersonal conflicts and conflicts leading to suicide (eg, by family conflict or emotional frustration) being the most commonly reported causes. Only $1.81 \%$ of posts published a multicausal explanation of suicides. This may be explained by the publisher intention to catch the reader's eye and gain clicks by describing suicide news in a conflicted and dramatic manner [38].

Second, suicides of older adults and rural residents were underreported. Our study demonstrated that the analyzed social media accounts put a disproportionate amount of focus on young adult suicide while rarely reporting on suicides among older

adults; in contrast, according to China's official health data reports, the suicide rate of people aged over 65 years is the highest among all age groups. For example, the average suicide rate of urban residents aged 65 to 85 years in 2018 was about 5.5 times higher than that of people aged 20 to 40 years (13.10 vs 2.39 per 100,000) [46]. In addition, the suicide rate of rural residents in China has always been higher than that of urban residents [46]. The underreporting of older adult suicide found in this study is consistent with the findings of Fu et al [23] for traditional newspapers. This reporting bias may pose a considerable risk for suicide prevention efforts; for example, policymakers may acknowledge the lack of reports and promote an unbalanced distribution of health resources. This type of bias may lead to the neglect of the suicides of vulnerable people by the general population, thus hindering people's ability to intervene and support those at risk for suicide. Given the specific context of the Chinese population, which has been experiencing rapid aging [47], such bias and the risk that it produces warrant great focus from researchers and practitioners.

In terms of suicide reporting quality, our results revealed that the analyzed social media accounts had low adherence to the WHO guidelines; this result echoed results found in previous Asian research [23-26]. Regarding harmful information, vividness of the reporting showed the worst performance; for traditional printed media, to reduce the risk of imitative suicide, publishers are advised to avoid placing suicide reporting in prominent positions of the printed news [20,38]. The research of Chu et al [25] found low compliance-23\% for newspaper articles-with the guideline to avoid prominent placement like the front page, boxes, or similar, but $85 \%$ for internet-based media articles. Our findings are likely to explain these differences further. Namely, although there is no fixed layout on social media, our results indicated that it uses alternative ways to capture readers' attention, such as using diverse internet 
elements (eg, hashtags and emojis). However, there are currently no standardized guidelines for their use. We are worried that this type of reporting style may be turning a serious public health issue into something that may be entertaining or even frivolous.

We also found that disclosure of private information showed a moderately problematic performance; almost half of the suicide reporting on the analyzed social media accounts exposed images of the person who died by suicide. This finding is concordant with the study of Fu et al [23] of Chinese newspapers (57.5\%) [23]; one possible explanation is that, as prior studies showed, Chinese people may be generally insensitive to privacy issues $[48,49]$. This conclusion can also be supported by research conducted in India, where $21.5 \%$ of the reporting contained photos of the person who died by suicide [24]. Also, a study on Facebook found that only $24 \%$ of suicide news disclosed a photo or video with information about the suicide site [36].

Our findings demonstrated that level of detail of the suicide description showed relevant noncompliance ratios; specifically, $24.01 \%$ of the suicide reporting provided an explicit description of the suicide method. This result is roughly consistent with prior studies on print newspapers in China and India [23,24]; however, since the speed and breadth of social media is greater than that of traditional media, we believe that even if it is roughly an equal proportion, social media may have a more profound negative impact.

Regarding helpful information, we found that the analyzed Chinese social media accounts provided very limited information on suicide prevention. WHO has suggested that mass media endeavor eliminate the general public's misconception about suicide and convey the view that mental illnesses and suicide are inseparable [20,50]. Unfortunately, less than $11 \%$ of the suicide reports in this study emphasized the relationship between mental health and suicidal behaviors. This result is consistent with previous research by Chu et al [25] which showed that less than $20 \%$ of the reported suicides (including in newspapers and websites) acknowledged the relationship between suicidal behavior and mental illness. However, in New Zealand, this proportion was more than 30\% [51] and in Australia, it was more than $50 \%$ of the analyzed samples [15]. To some extent, this shows the different attribution patterns of suicidal behavior in Chinese and Western media. Regarding information on support programs, our results showed that only 2 reports attached direct information on support programs like psychological intervention hotlines. This result echoes the findings on traditional media, suggesting that both traditional and social media do an inefficient job of providing information about support programs [23-25]. In addition, a US study on suicide reporting on Facebook revealed that $16 \%$ of suicide news contained a hotline phone number, a higher percentage than in China but still low overall [36]. In summary, while social media has tremendous convenience, such as link support resources, the potential of mainstream publishers to provide helpful information on suicide is currently underused.

\section{Implications}

For decades, academic and practical fields have been concerned with the quality of suicide reporting in the mainstream media. However, we have little information on how mainstream publishers report suicide via social media platforms. Although a recent study assessed suicide news on Facebook in English-speaking countries [36], empirical evidence on suicide reporting on Asian social media platforms, especially in China, is still very limited. Thus, we endeavored to examine adherence to WHO suicide guidelines on Chinese social media platforms; we intended to address the above mentioned gap by empirically investigating these reporting qualities.

Various studies have indicated that the degree of compliance with the WHO guidelines are affected by complex factors, including economic and media policy issues present in different countries [24,36,52]. Among them, culture is an important factor that cannot be ignored. This is evident in the Chinese and Western attributions regarding suicide. It is generally believed that China is an acquaintance society that attaches great importance to interpersonal relations. Therefore, Chinese society (including the media) focuses on suicide caused by interpersonal conflicts such as marriage and family conflicts. In contrast, the West tends to explain suicide in terms of pathology, emphasizing suicides that occur due to mental illness [53]. Our findings also confirm the cultural differences in suicide attribution between China and the West. Our study complements the current literature on suicide reporting in different cultural contexts, thereby indirectly supporting the cross-cultural study of suicide.

Our study has enormous practical implications for national-and potentially international—suicide prevention programs. First, for media practitioners, since we found that there was generally low compliance with WHO guidelines, we reiterate Chinese mainstream publishers' role as gatekeepers on social media platforms by encouraging the strengthening of editorial review policies to limit harmful information and disseminate helpful information. Since media practitioners' understanding and support of the guidelines will also affect the implementation of the guidelines [52], these publishers should focus on training and educating their social media professionals to enhance their knowledge of critical public health issues (eg, suicide).

Second, our study clarifies the role of the Ministry of Health in promoting responsible media practices; given that in China there are currently no national suicide reporting guidelines [54], one of the first tasks may be to develop national guidelines that align with the current condition of the media in the country. We suggest that an updated suicide reporting guideline document should fully consider the internet elements. Furthermore, considering that social media is constantly evolving and richer forms of media are likely to emerge in the future, the Ministry of Health should support the implementation of these guidelines and the development of supervisory tools to monitor and evaluate the quality of suicide reporting on social media on an ongoing basis.

Third, social organizations (eg, mental health institutions) can actively cooperate with mainstream publishers to increase dissemination of helpful information related to suicide on social media platforms. Prior studies have shown that stakeholders' active participation in the development of guidelines effectively boosts compliance with the guidelines [52,55]. Therefore, while social organizations provide professional knowledge on suicide 
prevention, social media can ensure that this knowledge is highly disseminated.

Last, users can play an active role in suicide prevention. On an interactive information platform, every click made by social media users can be regarded as a second transmission. The promotion and discussion of suicide topics on social networks may increase negative thoughts of suicide by members of vulnerable groups. It is necessary to help users safely convey information about suicide through social media [56]. Our results suggest that users should refrain from retweeting suicide reports that contain harmful information, such as those containing the private information of the people who died by suicide, and instead spread suicide-related articles with rich educational materials (eg, on psychological interventions and suicide prevention-related knowledge).

\section{Limitations}

This study has some limitations. First, since our data on suicide reporting came exclusively from the 10 most influential Chinese mainstream media accounts on Weibo, we did not include data from small-size media accounts, which may still play a meaningful role in particular and local issues. Thus, future evaluation research may include a greater variety of media types.
In addition, our study only assessed the suicide reporting of the analyzed publishers on Weibo; thus, future research can extend the analysis to other Chinese social media platforms (eg, WeChat) and attempt to conduct cross-cultural research on the topic of suicide on English-language social media platforms.

\section{Conclusions}

This study analyzed the characteristics of suicide reporting published by Chinese mainstream publishers via a social media platform and assessed the suicide reporting quality against WHO guidelines. Our findings illustrated that suicide reporting on social media by mainstream publishers in China disseminated too much harmful information, especially concerning the vividness of the reporting and disclosure of private information. Conversely, they provided minimal helpful information. Considering the tremendous information dissemination power of social media platforms, we highlight the need for the development of national suicide reporting guidelines that apply to the new media environment and local cultural backgrounds. We also recommend that social media practitioners, health care institutions, social organizations, and the public work together to promote responsible suicide reporting in the social media environment.

\section{Acknowledgments}

This work was partially supported by grant 19ZDA332 from the Major Project of the National Social Science Foundation of China.

\section{Conflicts of Interest}

None declared.

\section{References}

1. World Health Organization. Preventing suicide: a global imperative. 2014. URL: http://apps.who.int/iris/bitstream/10665/ 131056/1/9789241564779 eng.pdf?ua=1\&ua=1 [accessed 2020-11-19]

2. Public health action for the prevention of suicide: a framework. Geneva: World Health Organization; 2012. URL: http:/ lapps.who.int/iris/bitstream/10665/75166/1/9789241503570 eng.pdf?ua=1 [accessed 2020-12-03]

3. Maris RW. Suicide. Lancet 2002 Jul 27;360(9329):319-326. [doi: 10.1016/S0140-6736(02)09556-9] [Medline: 12147388]

4. Hawton K, van Heeringen K. The International Handbook of Suicide and Attempted Suicide. Chichester: Wiley; 2000.

5. Sisask M, Värnik A. Media roles in suicide prevention: a systematic review. Int J Environ Res Public Health 2012 Jan;9(1):123-138 [FREE Full text] [doi: 10.3390/ijerph9010123] [Medline: 22470283]

6. Hawton K, Williams K. The connection between media and suicidal behavior warrants serious attention. Crisis 2001;22(4):137-140. [doi: 10.1027//0227-5910.22.4.137] [Medline: 11848654]

7. Phillips DP. The influence of suggestion on suicide: substantive and theoretical implications of the Werther effect. Am Sociol Rev 1974;39(3):340-354. [Medline: 11630757]

8. Pirkis J, Blood RW. Suicide and the media. Part I: reportage in nonfictional media. Crisis 2001;22(4):146-154. [doi: 10.1027//0227-5910.22.4.146] [Medline: 11848658]

9. Stack S. Suicide in the media: a quantitative review of studies based on non-fictional stories. Suicide Life Threat Behav 2005 Apr;35(2):121-133. [doi: 10.1521/suli.35.2.121.62877] [Medline: 15843330]

10. Niederkrotenthaler T, Voracek M, Herberth A, Till B, Strauss M, Etzersdorfer E, et al. Role of media reports in completed and prevented suicide: Werther v. Papageno effects. Br J Psychiatry 2010 Sep;197(3):234-243. [doi:

10.1192/bjp.bp.109.074633] [Medline: 20807970]

11. Gould M, Jamieson P, Romer D. Media contagion and suicide among the young. Am Behav Sci 2003 May 01;46(9):1269-1284. [doi: 10.1177/0002764202250670] [Medline: 22973420]

12. Niederkrotenthaler T, Fu K, Yip PSF, Fong DYT, Stack S, Cheng Q, et al. Changes in suicide rates following media reports on celebrity suicide: a meta-analysis. J Epidemiol Community Health 2012 Nov;66(11):1037-1042. [doi: 10.1136/jech-2011-200707] [Medline: 22523342] 
13. Cheng ATA, Hawton K, Lee CTC, Chen THH. The influence of media reporting of the suicide of a celebrity on suicide rates: a population-based study. Int J Epidemiol 2007 Dec;36(6):1229-1234. [doi: 10.1093/ije/dym196] [Medline: 17905808]

14. Michel K, Frey C, Wyss K, Valach L. An exercise in improving suicide reporting in print media. Crisis 2000;21(2):71-79. [doi: 10.1027//0227-5910.21.2.71] [Medline: 11019482]

15. Pirkis J, Dare A, Blood RW, Rankin B, Williamson M, Burgess P, et al. Changes in media reporting of suicide in Australia between 2000/01 and 2006/07. Crisis 2009;30(1):25-33. [doi: 10.1027/0227-5910.30.1.25] [Medline: 19261565$]$

16. Fu KW, Yip PSF. Changes in reporting of suicide news after the promotion of the WHO media recommendations. Suicide Life Threat Behav 2008 Oct;38(5):631-636. [doi: 10.1521/suli.2008.38.5.631] [Medline: 19014313]

17. Etzersdorfer E, Sonneck G. Preventing suicide by influencing mass-media reporting. The Viennese experience $1980-1996$. Arch Suicide Res 1998 Jan;4(1):67-74. [doi: 10.1080/13811119808258290]

18. Niederkrotenthaler T, Herberth A, Sonneck G. [The "Werther-effect": legend or reality?]. Neuropsychiatr 2007;21(4):284-290. [Medline: $\underline{18082110}$ ]

19. Niederkrotenthaler T, Sonneck G. Assessing the impact of media guidelines for reporting on suicides in Austria: interrupted time series analysis. Aust N Z J Psychiatry 2007 May;41(5):419-428. [doi: 10.1080/00048670701266680] [Medline: 17464734]

20. Preventing suicide: a resource for media professionals. Geneva: World Health Organization; 2008. URL: https://apps. who.int/iris/bitstream/handle/10665/43954/9789241597074 eng.pdf?sequence=1\&isAllowed=y [accessed 2020-11-19]

21. Tatum PT, Canetto SS, Slater MD. Suicide coverage in U.S. newspapers following the publication of the media guidelines. Suicide Life Threat Behav 2010 Oct;40(5):524-534 [FREE Full text] [doi: 10.1521/suli.2010.40.5.524] [Medline: 21034215]

22. Creed M, Whitley R. Assessing fidelity to suicide reporting guidelines in Canadian news media: the death of Robin Williams. Can J Psychiatry 2017 May;62(5):313-317 [FREE Full text] [doi: 10.1177/0706743715621255] [Medline: 27600531]

23. Fu K, Chan Y, Yip PSF. Newspaper reporting of suicides in Hong Kong, Taiwan and Guangzhou: compliance with WHO media guidelines and epidemiological comparisons. J Epidemiol Community Health 2011 Oct;65(10):928-933. [doi: 10.1136/jech.2009.105650] [Medline: 20889589]

24. Armstrong G, Vijayakumar L, Niederkrotenthaler T, Jayaseelan M, Kannan R, Pirkis J, et al. Assessing the quality of media reporting of suicide news in India against World Health Organization guidelines: A content analysis study of nine major newspapers in Tamil Nadu. Aust N Z J Psychiatry 2018 Sep;52(9):856-863. [doi: 10.1177/0004867418772343] [Medline: 29726275]

25. Chu X, Zhang X, Cheng P, Schwebel DC, Hu G. Assessing the use of media reporting recommendations by the World Health Organization in suicide news published in the most influential media sources in China, 2003-2015. Int J Environ Res Public Health 2018 Mar 05;15(3):1 [FREE Full text] [doi: 10.3390/ijerph15030451] [Medline: 29510591]

26. Arafat SMY, Khan MM, Niederkrotenthaler T, Ueda M, Armstrong G. Assessing the quality of media reporting of suicide deaths in Bangladesh against World Health Organization guidelines. Crisis 2020 Jan;41(1):47-53. [doi:

10.1027/0227-5910/a000603] [Medline: 31140319]

27. Bertolote/, Fleischmann A. A global perspective in the epidemiology of suicide. Suicidology 2015 Jun 11;7(2):6-8. [doi: $10.5617 /$ suicidologi.2330]

28. Whiting A, Williams D. Why people use social media: a uses and gratifications approach. Qualitative Mrkt Res: An Int J 2013 Aug 30;16(4):362-369. [doi: 10.1108/QMR-06-2013-0041]

29. Moorhead SA, Hazlett DE, Harrison L, Carroll JK, Irwin A, Hoving C. A new dimension of health care: systematic review of the uses, benefits, and limitations of social media for health communication. J Med Internet Res 2013;15(4):e85 [FREE Full text] [doi: 10.2196/jmir.1933] [Medline: 23615206]

30. Xu S, Markson C, Costello KL, Xing CY, Demissie K, Llanos AA. Leveraging social media to promote public health knowledge: example of cancer awareness via twitter. JMIR Public Health Surveill 2016;2(1):e17 [FREE Full text] [doi: 10.2196/publichealth.5205] [Medline: 27227152]

31. García-Avilés JA, Kaltenbrunner A, Meier K. Media convergence revisited. J Pract 2014 Feb 28;8(5):573-584. [doi: $\underline{10.1080 / 17512786.2014 .885678]}$

32. Cao MY. [The writing and characteristics of Weibo news reports - take the news reports in People's Daily Weibo as an example]. J News Res 2015;6(11):152-153.

33. Tian H, Chang J. [The cultural transformation of party newspaper in the social media era: a case study based on the emotional expression of People's Daily]. Shanghai J Re 2019;1:1. [doi: 10.16057/j.cnki.31-1171/g2.2019.01.008]

34. Xiong Y. [Research on the status quo of People's Daily official Weibo communication]. Youth J 2014; 17:84-85. [doi: 10.15997/j.cnki.qnjz.2014.17.032]

35. Alvarez-Mon MA, Asunsolo Del Barco A, Lahera G, Quintero J, Ferre F, Pereira-Sanchez V, et al. Increasing interest of mass communication media and the general public in the distribution of tweets about mental disorders: observational study. J Med Internet Res 2018 May 28;20(5):e205 [FREE Full text] [doi: 10.2196/jmir.9582] [Medline: 29807880]

36. Sumner SA, Burke M, Kooti F. Adherence to suicide reporting guidelines by news shared on a social networking platform. Proc Natl Acad Sci U S A 2020 Jul 14;117(28):16267-16272 [FREE Full text] [doi: 10.1073/pnas.2001230117] [Medline: 32631982] 
37. World Health Organization. World health statistics overview 2019: monitoring health for the sustainable development goals. 2019. URL: https://apps.who.int/iris/bitstream/handle/10665/311696/WHO-DAD-2019.1-eng. pdf?sequence=1\&isAllowed=y [accessed 2020-11-19]

38. Chiang Y, Chung F, Lee C, Shih H, Lin D, Lee M. Suicide reporting on front pages of major newspapers in Taiwan violating reporting recommendations between 2001 and 2012. Health Commun 2016 Nov;31(11):1395-1404. [doi:

10.1080/10410236.2015.1074024] [Medline: 27007575]

39. China media convergence communication index in 2018. people.cn. URL: http://media.people.com.cn/n1/2019/0326/ c120837-30994743.html [accessed 2020-11-19]

40. Qi G, Abel F, Houben G, Yong Y. A comparative study of users' microblogging behavior on Sina Weibo and Twitter. 2012 Presented at: Proceedings of the International Conference on User Modeling; 2012; Montreal. [doi: $10.1007 / 978-3-642-31454-4 \quad 8]$

41. Tian X, Yu G, He F. An analysis of sleep complaints on Sina Weibo. Comput Human Behav 2016 Sep;62:230-235. [doi: 10.1016/j.chb.2016.04.014]

42. Lu P. [Content analysis of media suicide news: a perspective of spiritual healthy communication]. J Commun 2005;12:31-41.

43. Au JSK, Yip PSF, Chan CLW, Law YW. Newspaper reporting of suicide cases in Hong Kong. Crisis 2004;25(4):161-168. [doi: 10.1027/0227-5910.25.4.161] [Medline: 15580851]

44. McHugh ML. Interrater reliability: the kappa statistic. Biochem Med (Zagreb) 2012;22(3):276-282 [FREE Full text] [Medline: 23092060]

45. Eddleston M, Karalliedde L, Buckley N, Fernando R, Hutchinson G, Isbister G, et al. Pesticide poisoning in the developing world — a minimum pesticides list. Lancet 2002 Oct 12;360(9340):1163-1167. [doi: 10.1016/s0140-6736(02)11204-9] [Medline: 12387969$]$

46. China Health Statistics Yearbook. China Union Medical University Press. 2019. URL: https://data.cnki.net/area/Yearbook/ Single/N2020020200?z=D09 [accessed 2020-11-19]

47. Nie J. Erosion of eldercare in China: a socio-ethical inquiry in aging, elderly suicide and the government's responsibilities in the context of the one-child policy. Ageing Int 2016 Nov 7;41(4):350-365. [doi: 10.1007/s12126-016-9261-7]

48. McDougall BS. Privacy in modern China. History Compass 2004 Jan;2(1):1-8. [doi: 10.1111/j.1478-0542.2004.00097.x]

49. Wang Y, Norice G, Cranor L. Who is concerned about what? A study of American, Chinese and Indian users' privacy concerns on social network sites. Trust Trustworthy Comput 2011;6740:146-153. [doi: 10.1007/978-3-642-21599-5_11]

50. Nock MK, Hwang I, Sampson N, Kessler RC, Angermeyer M, Beautrais A, et al. Cross-national analysis of the associations among mental disorders and suicidal behavior: findings from the WHO World Mental Health Surveys. PLoS Med 2009 Aug;6(8):e1000123 [FREE Full text] [doi: 10.1371/journal.pmed.1000123] [Medline: 19668361]

51. McKenna B, Thom K, Edwards G. Reporting of Suicide in New Zealand Media: Content and Case Study Analysis. Auckland: Centre for Metal Health Research; 2010.

52. Bohanna I, Wang X. Media guidelines for the responsible reporting of suicide: a review of effectiveness. Crisis 2012;33(4):190-198. [doi: 10.1027/0227-5910/a000137] [Medline: 22713977]

53. Qin P, Mortensen PB. Specific characteristics of suicide in China. Acta Psychiatr Scand 2001 Feb;103(2):117-121. [doi: 10.1034/j.1600-0447.2001.00008.x] [Medline: 11167314]

54. Beautrais A, Hendin H, Yip P. Improving portrayal of suicide in the media in Asia. In: Hendin H, editor. Suicide and Suicide Prevention in Asia. Geneva: World Health Organization; 2008:39-50.

55. Collings SC, Kemp CG. Death knocks, professional practice, and the public good: the media experience of suicide reporting in New Zealand. Soc Sci Med 2010 Jul;71(2):244-248. [doi: 10.1016/j.socscimed.2010.03.017] [Medline: 20398990]

56. Robinson J, Hill NTM, Thorn P, Battersby R, Teh Z, Reavley NJ, et al. The \#chatsafe project. Developing guidelines to help young people communicate safely about suicide on social media: a Delphi study. PLoS One 2018 Nov 15;13(11):e0206584 [FREE Full text] [doi: 10.1371/journal.pone.0206584] [Medline: $\underline{30439958]}$

\section{Abbreviations}

WHO: World Health Organization

Edited by G Eysenbach; submitted 19.12.20; peer-reviewed by G Hu, A Teo, M Alvarez de Mon, S Byrne; comments to author 13.01.21; revised version received 07.03.21; accepted 15.04.21; published 13.05.21

Please cite as:

Lai K, Li D, Peng H, Zhao J, He L

Assessing Suicide Reporting in Top Newspaper Social Media Accounts in China: Content Analysis Study

JMIR Ment Health 2021;8(5):e26654

URL: https://mental.jmir.org/2021/5/e26654

doi: $\underline{10.2196 / 26654}$

PMID: 
(CKaisheng Lai, Dan Li, Huijuan Peng, Jingyuan Zhao, Lingnan He. Originally published in JMIR Mental Health (https://mental.jmir.org), 13.05.2021. This is an open-access article distributed under the terms of the Creative Commons Attribution License (https://creativecommons.org/licenses/by/4.0/), which permits unrestricted use, distribution, and reproduction in any medium, provided the original work, first published in JMIR Mental Health, is properly cited. The complete bibliographic information, a link to the original publication on https://mental.jmir.org/, as well as this copyright and license information must be included. 